\title{
Effectiveness of topical vancomycin in the prevention of spinal surgical site infections: a retrospective cohort study
}

\author{
Rawan T. Tafish' ${ }^{1}$ Ahmed F. Alkhaldi ${ }^{2}$, Anouar Bourghli ${ }^{1}$ and Turki A. Althunian² ${ }^{*}$ (D)
}

\begin{abstract}
Background: The risk of surgical site infections (SSIs), particularly methicillin-resistant Staphylococcus aureus (MRSA) SSIs, after spinal surgeries is one of the most daunting experiences to patients and surgeons. Some authors suggest applying vancomycin powder on the wound before skin closure to minimize the risk of SSIs; however, this practice is not supported by well-established evidence. This study sought to assess the effectiveness of topical (i.e. intra-wound) vancomycin in minimizing the risk of SSIs in patients who underwent spinal surgeries at a Saudi hospital.
\end{abstract}

Methods: A retrospective cohort study was conducted using the hospital database. Patients who underwent spinal surgeries from the period of 09/2013 to 09/2019 were included and followed up (observed from the time of the surgery) to 30 days (surgeries without implants) or 90 days (with implants). The odds ratio (OR) of the primary outcome between vancomycin treated versus non-treated patients was estimated using a logistic regression model adjusting for the measured confounders. A sensitivity analysis was conducted using propensity score analysis (inverse probability of treatment weighting [IPTW] with stabilized weights) to control for confounding by indication. All study analyses were completed using RStudio Version 1.2.5033.

Results: We included 81 vancomycin treated vs. 375 untreated patients with 28 infections (8/81 vs. 20/375; respectively). The adjusted OR of SSIs between the two groups was 0.40 ( $95 \%$ confidence interval [Cl] 0.11 to 1.34). The result of the propensity score analysis was consistent (OR: 0.97 [95\% Cl 0.35 to 2.68]).

Conclusions: We could not find a lower association of SSIs with intra-wound vancomycin in patients who underwent spinal surgeries. Further studies are needed to assess benefits of using topical vancomycin for this indication vs. the risk of antimicrobial resistance.

Keywords: Topical vancomycin, Spinal surgery, Surgical site infections, Antimicrobial resistance, Cohort study, Effectiveness

\section{Background}

Surgical site infections (SSIs) are the third most common complication among patients who underwent spinal surgeries with an overall prevalence of $3.1 \%$ (the prevalence is up $13.0 \%$ in the highest risk group) [1-3]. SSIs are defined as infections occurring after 30 days from the

\footnotetext{
*Correspondence: t.a.i.althunian@uu.nl

${ }^{2}$ Saudi Food and Drug Authority, Riyadh, Saudi Arabia

Full list of author information is available at the end of the article
}

operative procedure or up to 90 days in complicated deep incisions requiring implants [4]. They are burdensome complications and associated with a high risk of morbidity (especially readmission), mortality and economic loss [5]. In the United States, the direct and indirect health cost of SSIs after spinal surgeries is up to 10 billion dollars with a mortality rate of 8,000 deaths per year [6]. The risk is the highest among patients with thoracic spinal procedures $(3.7 \%)$, followed by the cervical and lumbar procedures (3.4 and $2.7 \%$ ), respectively [1]. The benefits original author(s) and the source, provide a link to the Creative Commons licence, and indicate if changes were made. The images or other third party material in this article are included in the article's Creative Commons licence, unless indicated otherwise in a credit line to the material. If material is not included in the article's Creative Commons licence and your intended use is not permitted by statutory regulation or exceeds the permitted use, you will need to obtain permission directly from the copyright holder. To view a copy of this licence, visit http://creativecommons.org/licenses/by/4.0/. The Creative Commons Public Domain Dedication waiver (http://creativeco mmons.org/publicdomain/zero/1.0/) applies to the data made available in this article, unless otherwise stated in a credit line to the data. 
of some preventive measures against SSIs using prophylactic antibiotic regimens (with cefazolin as a fixed component) have been outweighed by the risk of methicillin-resistant Staphylococcus aureus (MRSA) and coagulase-negative staphylococci (CoNS) [7-13]. This led to the off-label use of topical vancomycin (i.e. intra-wound) in some settings [14-44]

The off-label topical application of 1-2 g vancomycin powder from the injectable dosage forms for the prevention of SSIs after spinal surgeries is controversial [14-44]. The published studies on the effect of this application in the prevention of SSIs after spinal surgeries have shown mixed results, and none was conducted in Saudi Arabia (a recent study showed that the prevalence of MRSA infections was $19.1 \%$ at a Saudi tertiary hospital) [14-45]. Additionally, the design of these studies was subjected to several methodological limitations (e.g. the absence of a control group, the suboptimal choice of the control group, the suboptimal definition of the outcome, the suboptimal adjustment of potential measured confounders, ignoring the impact of some known effect modifiers, etc.). The aim of this study was to assess the effectiveness of topical vancomycin in the prevention of SSIs after spinal surgeries taking into consideration the aforementioned design limitations in a Saudi population.

\section{Methods}

\section{Source of data}

This retrospective cohort study was conducted using the database of a private hospital (the Kingdom Hospital) in Riyadh, Saudi Arabia. Data from the routine clinical care are added to the hospital's electronic health records. Diseases are coded using the International Statistical Classification of Diseases and Related Health Problems 10th Revision (ICD-10). Patient socio-demographic details, surgery type, relevant lab investigations (including culture sensitivity results), re-admission, follow-up periods and patient outcome were collected through a direct access to the electronic health records. Original patient medical charts were also accessed to collect missing values of the aforementioned variables and to collect data about additional covariates (past medical history, operation time, topical drug/intra-operative systemic drug exposure, and vital signs).

\section{Study cohort}

Patients who underwent spinal surgeries from the period of 09-2013 to 09-2019 were included. All patient visits to the hospital during the 90-day period after spinal surgeries were observed (either as scheduled or non-scheduled visits). Any infection (signs, symptoms and documented positive bacterial culture findings) that occurred within 30 days after the surgery (patients without implants) or
90 days (patients with implants) was considered as an SSI after spinal surgery (i.e. the outcome of the study). The infection was classified as deep or superficial based on the definition of the United States Center for Disease Control and Prevention (CDC) [46]. According to the CDC, superficial SSIs involve only the skin layer; other more serious SSIs which involve tissues under the skin, organs or implanted material can be considered as deep [46]. This follow-up period is reflective of the maximum follow-up period stated in the definition of SSIs after spinal surgeries in the "Introduction" section. All types of spinal surgeries were included in the study (i.e. lumbar, thoracic, thoracolumbar, and cervical) using the anterior or the posterior approach.

\section{Study exposure groups and outcome}

The included patients in this study were split into two exposure groups: a group with incident topical vancomycin treatment (test group) and another group of patients who were not treated with topical vancomycin (control group). The cohort entry date was defined as the date of the spinal surgery. The outcome was the first SSI observed in the follow-up period. For all patients in the test group, two-third of the vancomycin powder was first spread directly on the bones and muscles at the end of the surgery, then the remaining amount was applied between the fascia and the fat layer after fascia closure. Doses of vancomycin varied between 0.5 and $2 \mathrm{~g}$ based on the wound size and the type of the surgery, but the majority of patients received $1 \mathrm{~g}$ (61 of 81 [75\%]). MRSA screening was performed for 19 patients before the surgery, and colonization was identified in two patients (one received topical vancomycin). None of these two patients received any treatments before the surgery.

\section{Confounders}

The analysis of the study outcome was adjusted for the following potentially confounding variables: age, sex, body mass index (BMI), type of spinal surgery, smoking status, diabetes mellitus, kidney functions, hypertension, history of spinal surgeries, history of antibiotic use within 90 days before cohort entry date, prolonged operation time (an operation lasting $100 \mathrm{~min}$ or more), surgical approach (anterior vs. posterior), implants, use of disinfectants (alcohol, povidone-iodine, chlorhexidine), topical gentamicin solution for irrigation of wounds (i.e. applying the solution over the operation site) as one of the SSI prophylactic measures, pre- and post- operative inflammatory/infection markers such as white blood cell counts and neutrophil counts. These potential confounders were reported in the literature as potential risks for the outcome of the study with an assumption that none of them is an instrumental variable [1, 47-59]. 
Table 1 Baseline characteristics of the study groups

\begin{tabular}{|c|c|c|c|}
\hline Baseline characteristics & $\begin{array}{l}\text { Vancomycin treated } \\
\mathrm{N}=81\end{array}$ & $\begin{array}{l}\text { Vancomycin untreated } \\
\mathrm{N}=375\end{array}$ & $\begin{array}{l}\text { Difference } \\
\text { ( } p \text {-value) }\end{array}$ \\
\hline \multicolumn{4}{|l|}{ Age (years) } \\
\hline Median & 50 & 45 & \multirow[t]{2}{*}{0.06} \\
\hline IQR & 27 & 22 & \\
\hline \multicolumn{4}{|l|}{ Sexno. (\%) } \\
\hline Male & $47(58.0)$ & $249(66.4)$ & \multirow[t]{2}{*}{0.19} \\
\hline Female & $34(42.0)$ & $126(33.6)$ & \\
\hline \multicolumn{4}{|l|}{$B M I\left(\mathrm{~kg} / \mathrm{m}^{2}\right)$} \\
\hline Median & 29.7 & 29.4 & \multirow[t]{2}{*}{0.52} \\
\hline IQR & 8.4 & 7.2 & \\
\hline \multicolumn{4}{|l|}{ Type of surgery no. (\%) } \\
\hline Lumbar & $58(72.0)$ & $285(76.0)$ & \multirow[t]{4}{*}{$<0.01$} \\
\hline Thoracic & $5(6.0)$ & $5(1.0)$ & \\
\hline Thoracolumbar & $15(18.0)$ & $30(8.0)$ & \\
\hline Cervical & $3(4.0)$ & $55(15.0)$ & \\
\hline \multicolumn{4}{|l|}{ Smoking history no. (\%) } \\
\hline Never smokers & $60(74.0)$ & $232(62.0)$ & \multirow[t]{3}{*}{0.12} \\
\hline Current smokers & $19(23.0)$ & $125(33.3)$ & \\
\hline Former smokers & $2(3.0)$ & $18(5.0)$ & \\
\hline Diabetes mellitus no. (\%) & $20(25.0)$ & $64(17.0)$ & 0.14 \\
\hline \multicolumn{4}{|l|}{ Renal functions no. (\%) } \\
\hline Normal & $79(98.0)$ & $371(99.0)$ & \multirow[t]{2}{*}{0.28} \\
\hline Abnormal & $2(2.0)$ & $4(1.0)$ & \\
\hline Hypertension no. (\%) & $29(36.0)$ & $98(26.0)$ & 0.10 \\
\hline History of spinal infection no. (\%) & $4(5.0)$ & $3(1.0)$ & 0.02 \\
\hline History of spinal surgeries no. (\%) & $19(23.0)$ & $54(14.0)$ & 0.06 \\
\hline $\begin{array}{l}\text { History of antibiotic use within } 90 \text { days before index } \\
\text { date no. (\%) }\end{array}$ & $13(16.0)$ & $28(8.0)$ & 0.03 \\
\hline Prolonged operation time no. (\%) & $71(88.0)$ & $29(8.0)$ & $<0.01$ \\
\hline \multicolumn{4}{|l|}{ Surgical approach no. (\%) } \\
\hline Anterior & $0(0.0)$ & $31(8.0)$ & \multirow[t]{2}{*}{$<0.01$} \\
\hline Posterior & $81(100.0)$ & $344(92.0)$ & \\
\hline Implant no. (\%) & $72(89.0)$ & $184(49.0)$ & $<0.01$ \\
\hline Alcohol as disinfectant no. (\%) & $70(86.0)$ & $303(81.0)$ & 0.30 \\
\hline Prophylactic gentamicin solution for irrigation no. (\%) & $68(84.0)$ & $281(75.0)$ & 0.11 \\
\hline \multicolumn{4}{|l|}{ Pre-operative white blood cell counts (in $10 \wedge 3 / \mu$ l) } \\
\hline Median & 7.5 & 8.2 & \multirow[t]{2}{*}{0.08} \\
\hline IQR & 3.8 & 3.1 & \\
\hline \multicolumn{4}{|l|}{ Pre-operative neutrophil counts (\%) } \\
\hline Median & 54.7 & 57.4 & \multirow[t]{2}{*}{0.13} \\
\hline IQR & 13.9 & 13.9 & \\
\hline
\end{tabular}

No prolonged antibiotic treatment was given to any of the patients in this study (as recommended by the hospital guideline). All patients were given a prophylactic systemic cefazolin intravenous injection within $60 \mathrm{~min}$ before the scheduled surgeries (doses of 1-2 $\mathrm{g}$ with patients above $80 \mathrm{~kg}$ receiving the $2 \mathrm{~g}$ dose). The systemic prophylactic cefazolin dose was repeated in case of high blood loss or during a long surgical intervention (i.e. if the surgery time exceeded two cefazolin half-lives). All surgeries in the study were performed by the same surgeon.

\section{Statistical analysis}

The primary hypothesis of the study was that topical vancomycin use is superior to non-vancomycin use in the 
prevention of SSIs after spinal surgeries. This hypothesis was tested using a logistic regression model adjusting for the measured confounders. The observed number of the primary outcome events was low; therefore, the odds ratio (OR) estimated from the model would provide a close approximation of the relative risk.

During the study period, there was a tendency to use intraoperative topical vancomycin for patients who are at high risk of SSIs after spinal surgeries (those who were scheduled for implants or those with a history of spinal infections). Thus, a sensitivity analysis was conducted using propensity score analysis to take into account the possible risk of confounding by indication [60-63]. In the first step, propensity scores (the probability of assignment to vancomycin group) for the included patients were estimated using a logistic regression model incorporating all study measured confounders. Then, a propensity score analysis was conducted using inverse probability of treatment weighting (IPTW) with stabilized weights. The balance check in the new "pseudo-population" was based on the absolute standardized difference (a balance was achieved if the difference was $<10 \%$ ). All statistical analyses were conducted using RStudio Version 1.2.5033.

\section{Results}

We included 456 patients who were either treated with topical vancomycin $(n=81)$ or without an exposure to topical vancomycin $(n=375)$ (Table 1 . Most patients underwent lumbar surgeries (343 of 456 [75\%]), most surgeries had a posterior approach (425 of 456 [93\%]), and more than two-third of patients were given prophylactic gentamicin solution for irrigation (349 of 456 [77\%]). None of the patients experienced systemic adverse events.

A total of 28 cases of SSIs after spinal surgeries were identified in vancomycin treated vs. untreated groups ( 8 of 81 [9.9\%] vs. 20 of 375 [5.3\%], respectively), and the median time to the occurrence of the infection was 14 days. Out of 28 infections, 16 (57\%) were considered deep and 12 (43\%) were superficial (Table 2). Some patients were infected by more than 1 isolated pathogens which explains the higher number of the total isolated microbes compared with the number of SSI cases (36 vs. 28 respectively), (Table 3). The microbiological analysis revealed that $50 \%(14 / 28)$ of these SSIs were caused by Staphylococcus species (4 vs. 10 in vancomycin treated and untreated groups; respectively), (Table 3). The other $50 \%$ were caused mostly by Gram negative bacteria such as Klebsiella pneumoniae, Pseudomonas aeruginosa, and Escherichia coli isolates (Table 3). The distribution of Gram positive and polymicrobial/Gram negative SSIs was similar between vancomycin treated vs. untreated groups. The odds of SSIs in the vancomycin
Table 2 Microbiological analysis of the identified SSIs

\begin{tabular}{|c|c|c|}
\hline Isolated microbe & $\begin{array}{l}\text { Deep } \\
\text { infections } \\
\text { (n) }\end{array}$ & $\begin{array}{l}\text { Superficial } \\
\text { infections }(n)\end{array}$ \\
\hline Mycobacterium tuberculosis & 2 & 0 \\
\hline $\begin{array}{l}\text { Methicillin susceptible Staphylococcus } \\
\text { aureus }\end{array}$ & 3 & 5 \\
\hline Klebsiella pneumoniae & 1 & 0 \\
\hline Klebsiella pneumoniae -ESBL* & 2 & 1 \\
\hline Pseudomonas aeruginosa & 4 & 2 \\
\hline Escherichia coli & 0 & 2 \\
\hline Enterobacter cloacae-MDR**, & 1 & 0 \\
\hline Morganella morganii & 2 & 0 \\
\hline Acinetobacter baumannii & 1 & 0 \\
\hline MRSA & 4 & 0 \\
\hline Escherichia coli -ESBL* & 1 & 1 \\
\hline Coagulase-Negative Staphylococci ${ }^{ \pm}$ & 0 & 4 \\
\hline Total number & 21 & 15 \\
\hline
\end{tabular}

${ }^{*} E S B L$ extended-spectrum beta-lactamase

**MDR multi-drug resistant

\pm Coagulase negative staphylococci: two isolates were Staphylococcus epidermidis and Staphylococcus hominis. The other two isolates were not identified

group was comparable to the odds in the non-exposure group: $\mathrm{OR}=0.40$ (95\% confidence interval $[\mathrm{CI}] 0.11$ to 1.34). The results of propensity score estimation showed a clear evidence of confounding by indication (i.e. a large proportion of the patients in the non-exposure group had a propensity of zero) as shown in Fig. 1, which also prevented trimming of the extreme values. The balance was achieved in $50 \%$ of the variables in the pseudo-population. The result of the IPTW analysis was consistent with the results of the first analysis; however, the direction of the point estimate shifted to the null value: $\mathrm{OR}=0.97$ (95\%CI 0.35 to 2.68 ).

\section{Discussion}

This study found a comparable risk of SSIs after spinal surgeries between the topically vancomycin treated vs. untreated patients. Nevertheless, the findings of the original and sensitivity analyses showed that the usefulness of topical vancomycin in this context would benefit from the conduct of additional multicenter studies with the inclusion of a larger number of patients.

The risk of SSIs after spinal surgeries between the vancomycin treated vs. untreated groups in our study was found to be comparable, which was similar to the findings of two-third of the published studies (20 of 30 [67\%]) that assessed the effectiveness of vancomycin in this patient group [14-44]. The risk in the topical vancomycin group in the largest of those studies varies from being lower, to 


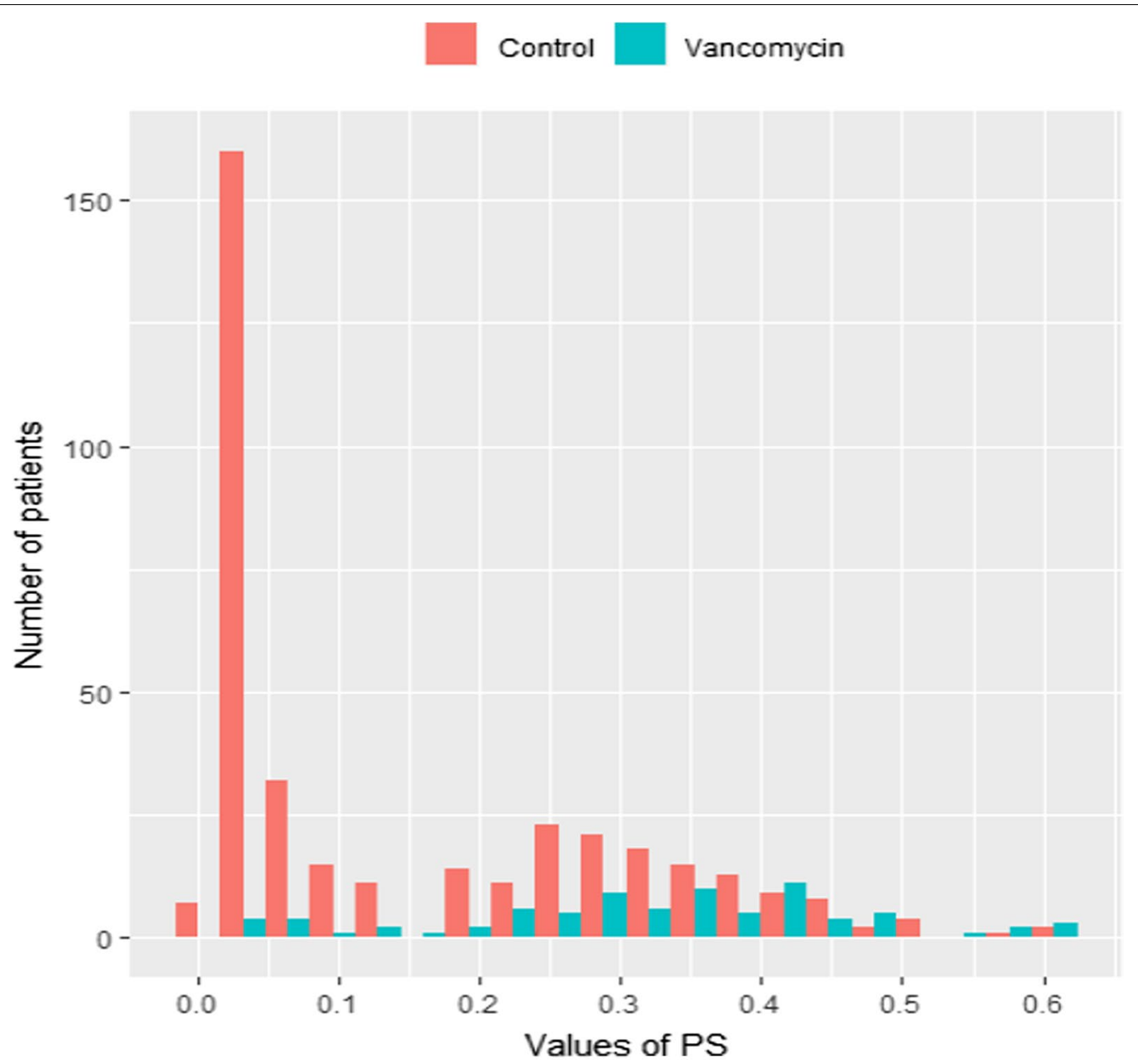

Fig. 1 Propensity score distribution in the vancomycin (test) vs. control (non-user) groups

Table 3 Isolated microbes in infected Vancomycin treated and Vancomycin untreated patients

\begin{tabular}{llll}
\hline Isolated microbe* & $\begin{array}{l}\text { Total number of isolates } \\
\mathbf{N}=\mathbf{3 6}\end{array}$ & $\begin{array}{l}\text { Vancomycin treated } \\
\mathbf{N}=\mathbf{1 1}\end{array}$ & $\begin{array}{c}\text { Vancomycin } \\
\text { untreated } \\
\mathbf{N}=\mathbf{2 5}\end{array}$ \\
\hline Methicillin-susceptible Staphylococcus aureus no. (\%) & 8 & $1(9 \%)$ & $7(28 \%)$ \\
MRSA no. (\%) & 4 & $2(18 \%)$ & $2(8 \%)$ \\
Coagulase-negative Staphylococci no. (\%) ${ }^{ \pm}$ & 4 & $2(18 \%)$ & $2(8 \%)$ \\
Klebsiella pneumoniae & 4 & $1(9 \%)$ & $3(12 \%)$ \\
Escherichia coli & 4 & $2(18 \%)$ & $2(8 \%)$ \\
Enterobacter cloacae & 1 & $1(0 \%)$ & $1(4 \%)$ \\
Morganella morganii & 2 & $1(9 \%)$ & $1(4 \%)$ \\
Pseudomonas aeruginosa & 6 & $0(0 \%)$ & $5(20 \%)$ \\
Mycobacterium tuberculosis & 2 & $1(9 \%)$ & $2(8 \%)$ \\
Acinetobacter baumannii & 1 & $0(0 \%)$ &
\end{tabular}

*Samples for culture sensitivity were taken from a swab as deep as possible during the follow-up visits upon the presence of signs/symptoms of infection. Tissue samples (e.g. bone or fascia) were taken in the operation room under general anesthesia in case of revision/debridement. Species confirmation was performed using Vitek $^{\circledR}$ System

\pm One isolate was methicillin- susceptible Staphylococcus hominis, the other was methicillin- resistant Staphylococcus epidermidis. The species of the other two isolates were not identified, but one was methicillin resistant and the other was methicillin susceptible

\& Assessment for Mycobacterium tuberculosis was performed for patients with signs/symptoms and/or history of tuberculosis infection 
comparable, or even to higher vs. the groups who were not treated with topical vancomycin. Nevertheless, the analysis of this risk in most of the published studies was not adjusted for the known measured confounders, and the risk of confounding by indication was taken into account only in two of these studies [25, 27, 28, 32, 38]. Additionally, the risk in two of the largest studies was assessed without a control group (i.e. in a pre and post fashion) $[25,27]$. The evidence from three randomized controlled trials was not conclusive since two trials were open-label, and two of were stopped prematurely $[17,37$, 41]. The risk of SSIs in our study was comparable to that in the two studies in which confounding by indication was taken into account by propensity score analysis [28, 38]. The propensity score model in our study showed that the use of topical vancomycin is being channeled to the group of patients who are at higher risk of SSIs after spinal surgeries. The effect of confounding by indication was also clear in the shift of the effect from an OR of 0.4 in the logistic regression towards the null value $(\mathrm{OR}=0.97)$ in the IPTW analysis.

Doses of topical vancomycin in the published studies ranged from 0.5 to $2 \mathrm{~g}$, most utilized a prophylactic cefazolin dose, and most were designed as retrospective cohort studies. It is anticipated that the effect of the topical vancomycin would be instantaneous and would last for the entire follow-up period (the concentrations are known to be high with a low systemic absorption) [64]. The findings of our study showed that the distribution of Gram positive and polymicrobial/Gram negative SSIs was similar in both groups. This was different from their distribution in most published studies in which the risks of Gram positive pathogens (i.e. Staphylococcus species) and polymicrobial/Gram negative pathogens in the vancomycin-treated group were lower and higher, respectively $[42,43]$. No systemic adverse events were observed in our study which is consistent with the findings from the literature (only two of over 2000 topical vancomycin administrations were associated with systemic adverse events) [64].

Our study was the first to assess the effectiveness of topical vancomycin in minimizing the risk of SSIs after spinal surgeries in the Gulf region. Additionally, it was one of the few observational studies in this context that took confounding by indication into account with a good level of completeness of the measured confounders. Another strength in the study was the sufficient follow up period (30-90 days) giving that 30-days follow up by the same surgeon was completed for almost $94 \%$ of the patient population, rendering the risk of outcome misclassification. The main limitation in our study was that it was limited to a single center. Addtionally, the lack of randomization prevented us from having a structured intervention and documentation (as well as adjusting for all types of confounders). The inclusion of more centers (especially the largest ones) in future studies would improve the generalizability of the assessment.

\section{Conclusions}

To conclude, we could not find a lower risk of SSIs after spinal surgeries with the use of topical vancomycin. Further studies are needed to assess benefits of using topical vancomycin for this indication vs. the risk of antimicrobial resistance.

\section{Abbreviations}

SSIs: Aurgical site infections; MRSA: Methicillin-resistant Staphylococcus aureus; OR: Odds ratio; IPTW: Inverse probability of treatment weighting; ICD-10: International Statistical Classification of Diseases and Related Health Problems 10th Revision; BMI: Body mass index.

\section{Acknowledgements}

We thank the information technology (IT) and the medical records (MR) departments at the Kingdom Hospital for their help in accessing the patient records and retrieving the data required for this research.

\section{Funding \\ No funding was provided for this study. Data included in this study were generated as part of the routine daily work.}

\section{Availability of data and materials}

The datasets generated and/or analysed during the current study are not publicly available due [patient confidential data] but the anonymized datasets are available from the corresponding author on reasonable request.

\section{Declarations}

\section{Ethics approval and consent to participate}

A protocol for the study was submitted to the Institutional Review Board (IRB) at the hospital and an approval was granted on 5/2019 by the IRB. The views expressed in this paper are those of the author(s) and not do not necessarily reflect those of the SFDA or its stakeholders.

\section{Competing interests}

The authors declare that they have no competing interests.

\section{Author details \\ ${ }^{1}$ Kingdom Hospital and Consulting Clinics, Riyadh, Saudi Arabia. ${ }^{2}$ Saudi Food and Drug Authority, Riyadh, Saudi Arabia.}

Received: 12 June 2021 Accepted: 7 September 2021

Published online: 26 September 2021

\section{References}

1. Jiaming $Z$, Wang $R$. Incidence of surgical site infection after spine surgery: a systematic review and meta-analysis. SPINE. 2019;45(3):208-16.

2. The French Orthopaedic Surgery Traumatology Society. Early surgical site infections in adult spinal trauma: a prospective, multi-center study of infection rates and risk factors. Orthop Traumatol Surg Res. 2012;98:788-94.

3. Saeedinia S, Nouri M, Azarhomayoun A, et al. The incidence and risk factors for surgical site infection after clean spinal operations: a prospective cohort study and review of the literature. Surg Neurol Int. 2015;6:154.

4. World Health Organization WHO. Protocol for surgical site infection surveillance with a focus on settings with limited resources. 2018. 
5. Anderson PA, Savage JW, Vaccaro AR, et al. Prevention of surgical site infection in spine surgery. Neurosurgery. 2017;80(3S):S114-23.

6. Hidron Al, Edwards JR, Patel J, et al. Antimicrobial-resistant pathogens associated with healthcare-associated infections: annual summary of data reported to the national healthcare safety network at the Centers for Disease Control and Prevention. Infect Control Hosp Epidemiol. 2008;29(11):996-1011.

7. ASHP therapeutic guidelines on antimicrobial prophylaxis in surgery. Am J Health Syst Pharm. 1999;56(18):1839-88.

8. National Healthcare Safety Network (NHSN). Patient Safety Component Manual. Surgical site infection event. 2019.

9. Scottish Intercollegiate Guidelines Network (SIGN). Antibiotic prophylaxis in surgery. 2014.

10. Bratzler DW, Dellinger EP, Olsen KM, et al. Clinical practice guidelines for antimicrobial prophylaxis in surgery. Am J Health Syst Pharm. 2013;70(3):195-283.

11. Berríos-Torres SI, Umscheid A, Bratzler DW, et al. Centers for Disease Control and Prevention guideline for the prevention of surgical site infection. JAMA Surg. 2017;152(8):784-91.

12. Rubinstein $E$, Findler $G$, Amit $P$, et al. Perioperative prophylactic cephazolin in spinal surgery: A double-blind placebo controlled trial. J Bone Joint Surg Br. 1994;76(1):99-102.

13. Margaryan D, Renz N, Bervar M, et al. Spinal implant-associated infections: a prospective multicentre cohort study. Int J Antimicrob Agents. 2020;56(4):106116.

14. Sweet FA, Roh M, Sliva C. Intra-wound application of vancomycin for prophylaxis in instrumented thoracolumbar fusions: efficacy, drug levels, and patient outcomes. Spine (Phila Pa 1976). 2011;36(24):2084-8.

15. O'Neill KR, Smith JG, Abtahi AM, et al. Reduced surgical site infections in patients undergoing posterior spinal stabilization of traumatic injuries using vancomycin powder. Spine J. 2011;11(7):641-6.

16. Caroom C, Tullar JM, Benton Jr EG, et al. Intrawound vancomycin powder reduces surgical site infections in posterior cervical fusion. Spine (Phila Pa 1976). 2013;38(14):1183-7.

17. Pahys JM, Pahys JR, Cho SK, et al. Methods to decrease postoperative infections following posterior cervical spine surgery. J Bone Joint Surg Am. 2013;95(6):549-54.

18. Tubaki VR, Rajasekaran S, Shetty AP. Effects of using intravenous antibiotic only versus local intra-wound vancomycin antibiotic powder application in addition to intravenous antibiotics on postoperative infection in spine surgery in 907 patients. Spine (Phila Pa 1976). 2013;38(25):2149-55.

19. Kim HS, Lee SG, Kim WK, et al. Prophylactic intra-wound application of vancomycin powder in instrumented spinal fusion surgery. Korean J Spine. 2013;10(3):121-5.

20. Strom RG, Pacione D, Kalhorn SP, et al. Lumbar laminectomy and fusion with routine local application of vancomycin powder: decreased infection rate in instrumented and non-instrumented cases. Clin Neurol Neurosurg. 2013;115(9):1766-9.

21. Strom RG, Pacione D, Kalhorn SP, et al. Decreased risk of wound infection after posterior cervical fusion with routine local application of vancomycin powder. Spine (Phila Pa 1976). 2013;38:991-4.

22. Godil SS, Parker SL, O'Neill KR, et al. Comparative effectiveness and cost-benefit analysis of local application of vancomycin powder in posterior spinal fusion for spine trauma: clinical article. J Neurosurg Spine. 2013;19(3):331-5.

23. Theologis AA, Demirkiran G, Callahan M, et al. Local intra-wound vancomycin powder decreases the risk of surgical site infections in complex adult deformity reconstruction: a cost analysis. Spine (Phila Pa 1976). 2014;39:1875-80.

24. Hill BW, Emohare O. The use of vancomycin powder reduces surgical reoperation in posterior instrumented and non-instrumented spinal surgery. Acta Neurochir (Wien). 2014;156:749-54.

25. Martin JR, Adogwa O, Brown CR, et al. Experience with intra-wound vancomycin powder for spinal deformity surgery. Spine (Phila Pa 1976), 2014;39(2):177-84.

26. Ghobrial GM, Thakkar V, Andrews E, et al. Intraoperative vancomycin use in spinal surgery: single institution experience and microbial trends. Spine (Phila Pa 1976). 2014;39)(7):550-5.

27. Heller A, Mclff TE, Lai SM, et al. Intrawound vancomycin powder decreases Staphylococcal surgical site infections after posterior instrumented spinal arthrodesis. J Spinal Disord Tech. 2015;28(10):E584-9.
28. Tomov M, Mitsunaga L, Durbin-Johnson B, et al. Reducing surgical site infection in spinal surgery with betadine irrigation and intra-wound vancomycin powder. Spine (Phila Pa 1976). 2015;40(7):491-9.

29. Martin JR, Adogwa O, Brown CR, et al. Experience with intrawound vancomycin powder for posterior cervical fusion surgery. J Neurosurg Spine. 2015;22(1):26-33.

30. Liu N, Wood KB, Schwab JH, et al. Comparison of intra-wound vancomycin utility in posterior instrumented spine surgeries between patients with tumor and non-tumor patients. Spine (Phila Pa 1976). 2015;40(20):1586-92.

31. Lee Gl, Bak KH, Chun HJ, et al. Effect of using local intra-wound vancomycin powder in addition to intravenous antibiotics in posterior lumbar surgery: midterm result in a single-center study. Korean J Spine. 2016;13:47-52.

32. Gaviola A, McMillian WD, Ames SE, et al. A retrospective study on the protective effects of topical vancomycin in patients undergoing multilevel spinal fusion. Pharmacotherapy. 2016;36(1):19-25.

33. Schroeder JE, Girardi FP. The use of local vancomycin powder in degenerative spine surgery. Eur Spine J. 2016;25(4):1029-33.

34. Chotai S, Wright PW, Hale AT, et al. Does intrawound vancomycin application during spine surgery create vancomycin-resistant organism? Neurosurgery. 2017;80(5):746-53.

35. Hey HW, Thiam DW, Koh ZSD, et al. Is intraoperative local vancomycin powder the answer to surgical site infections in spine surgery? Spine (Phila Pa 1976). 2017;42(4):267-74.

36. Van Hal M, Lee J, Laudermilch D, et al. Vancomycin powder regimen for prevention of surgical site infection in complex spine surgeries. Clin Spine Surg. 2017;30:E1062-5.

37. Hida T, Ando K, Kobayashiet K, et al. Intrawound vancomycin powder as the prophylaxis of surgical site infection after invasive spine surgery with a high risk of infection. Nagoya J Med Sci. 2017;79:545-50.

38. Mirzashahi B, Chehrassan M, Mortazavi SMJ. Intrawound application of vancomycin changes the responsible germ in elective spine surgery without significant effect on the rate of infection: a randomized prospective study. Musculoskelet Surg. 2018;102:35-9.

39. Horii C, Yamazaki T. Does intrawound vancomycin powder reduce surgical site infection after posterior instrumented spinal surgery? A propensity score-matched analysis. Spine J. 2018;18(12):2205-12.

40. Sumeet G, Bloch N, Potter M, et al. Topical vancomycin in pediatric spine surgery does not reduce surgical site infection: a retrospective cohort study. Spine Deform. 2018;6(5):523-8.

41. Haimoto S, Schär RT, Nishimura Y, et al. Reduction in surgical site infection with supra-fascial intra-wound application of vancomycin powder in instrumented posterior spinal fusion: a retrospective case-control study. J Neurosurg Spine. 2018;29(2):193-8.

42. Dodson V, Majmundar N, Swantic V, et al. The effect of prophylactic vancomycin powder on infections following spinal surgeries: a systematic review. Neurosurg Focus. 2019;1:E11.

43. Gande A, Rosinski A, Cunningham T, et al. Selection pressures of vancomycin powder use in spine surgery: a meta-analysis. Spine J. 2019;19(6):1076-84

44. Takeuchi M, Wakao N, Mitsuhiro K, et al. A double-blind randomized controlled trial of the local application of vancomycin versus ampicillin powder into the operative field for thoracic and/or lumbar fusions. J Neurosurg Spine. 2018;29:553-9.

45. Alhunaif SA, Almansour S, Almutairi R, et al. Methicillin-Resistant Staphylococcus Aureus Bacteremia: Epidemiology, Clinical Characteristics, Risk Factors, and Outcomes in a Tertiary Care Center in Riyadh, Saudi Arabia. Cureus. 2021;13(5):e14934.

46. Center for Disease Control and Prevention. Surgical site infections. 2010. https://www.cdc.gov/hai/ssi/ssi.html. Accessed Aug 2021.

47. Carreon LY, Puno RM, Dimar 2nd JR, et al. Perioperative complications of posterior lumbar decompression and arthrodesis in older adults. Am J Bone Joint Surg. 2003;85(11):2089-92.

48. ter Gunne AFP, Cohen DB. Incidence, prevalence, and analysis of risk factors for surgical site infection following adult spinal surgery. Spine. 2009;34:1422-8.

49. Zhang L, Li N. Risk factors for surgical site infection following lumbar spinal surgery: a meta-analysis. Ther Clin Risk Manag. 2018;14:2161-9. 
50. Cizik AM, Lee MJ, Martin Bl, et al. Using the Spine Surgical Invasiveness Index to identify risk of surgical site infection. Am J Bone Joint Surg. 2012;94(4):335-42.

51. De la Garza-Ramos R, Bydon M, Abt NB, et al. The impact of obesity on short- and long-term outcomes after lumbar fusion. Spine (Phila Pa 1976). 2014;40(1):56-61.

52. Marquez-Lara A, Nandyala SV, Sankaranarayanan S, et al. Body mass index as a predictor of complications and mortality after lumbar spine surgery. Spine (Phila Pa 1976). 2014:39(10):798-804.

53. Martin CT, Gao Y, Duchman KR, et al. The impact of current smoking and smoking cessation on short-term morbidity risk after lumbar spine surgery. Spine (Phila Pa 1976). 2016;41(7):577-84.

54. Olsen MA, Nepple JJ, Riew KD, et al. Risk factors for surgical site infection following orthopaedic spinal operations. Am J Bone Joint Surg. 2008;90(1):62-9.

55. Atesok K, Papavassiliou E, Heffernan MJ, et al. Current strategies in prevention of postoperative infections in spine surgery. Global Spine J. 2020;10(2):183-94.

56. Hidron Al, Kourbatova EV, Halvosa JS, et al. Risk factors for colonization with methicillin-resistant Staphylococcus aureus (MRSA) in patients admitted to an urban hospital: emergence of community-associated MRSA nasal carriage. Clin Infect Dis. 2005;41(2):159-66.

57. Boston KM, Baraniuk S, O'Heron S, et al. Risk factors for spinal surgical site infection, Houston, Texas. Infect Control Hosp Epidemiol. 2009;30(9):884-9.
58. Lee NJ, Shin JI, Kothari P, et al. Incidence, impact, and risk factors for 30-day wound complications following elective adult spinal deformity surgery. Global Spine J. 2017;7(5):417-24.

59. Smith JS, Shaffrey Cl, Sansur CA, et al. Rates of infection after spine surgery based on 108,419 procedures: a report from the scoliosis research society morbidity and mortality committee. Spine (Phila Pa 1976). 2011:36(7):556-63.

60. Rosenbaum PR, Rubin DB. The central role of the propensity score in observational studies for causal effects. Biometrika. 1983;70:41-55.

61. Rosenbaum PR, Rubin DB. Reducing bias in observational studies using subclassification on the propensity score. J Am Stat Assoc. 1984;79:516-24.

62. Cole SR, Hernán MA. Constructing inverse probability weights for marginal structural models. Am J Epidemiol. 2008;168(6):656-64.

63. Ali MS, Prieto-Alhambra D, Lopes LC, et al. Propensity score methods in health technology assessment: principles, extended applications, and recent advances. Front Pharmcol. 2019;10:973.

64. Abdullah KG, Chen HI, Lucas TH. Safety of topical vancomycin powder in neurosurgery. Surg Neuro Int. 2016;7(Supp 39):919-26.

\section{Publisher's Note}

Springer Nature remains neutral with regard to jurisdictional claims in published maps and institutional affiliations.
Ready to submit your research? Choose BMC and benefit from:

- fast, convenient online submission

- thorough peer review by experienced researchers in your field

- rapid publication on acceptance

- support for research data, including large and complex data types

- gold Open Access which fosters wider collaboration and increased citations

- maximum visibility for your research: over $100 \mathrm{M}$ website views per year

At BMC, research is always in progress.

Learn more biomedcentral.com/submissions 